\title{
Parametric Investigations at the Head-Disk Interface of Thermal Fly-Height Control Sliders in Contact
}

\author{
Sripathi V. Canchi, ${ }^{1}$ David B. Bogy, ${ }^{1}$ Run-Han Wang, ${ }^{2}$ and Aravind N. Murthy ${ }^{2}$ \\ ${ }^{1}$ Computer Mechanics Laboratory, Mechanical Engineering, University of California, Berkeley, CA 94720, USA \\ ${ }^{2}$ HGST, a Western Digital Company, San Jose, CA 95135, USA
}

Correspondence should be addressed to Sripathi V. Canchi, sripathi.canchi@cal.berkeley.edu

Received 3 August 2012; Accepted 12 November 2012

Academic Editor: Bo Liu

Copyright (C) 2012 Sripathi V. Canchi et al. This is an open access article distributed under the Creative Commons Attribution License, which permits unrestricted use, distribution, and reproduction in any medium, provided the original work is properly cited.

\begin{abstract}
Accurate touchdown power detection is a prerequisite for read-write head-to-disk spacing calibration and control in current hard disk drives, which use the thermal fly-height control slider technology. The slider air bearing surface and head gimbal assembly design have a significant influence on the touchdown behavior, and this paper reports experimental findings to help understand the touchdown process. The dominant modes/frequencies of excitation at touchdown can be significantly different leading to very different touchdown signatures. The pressure under the slider at touchdown and hence the thermal fly-height control efficiency as well as the propensity for lubricant pickup show correlation with touchdown behavior which may be used as metrics for designing sliders with good touchdown behavior. Experiments are devised to measure friction at the head-disk interface of a thermal flyheight control slider actuated into contact. Parametric investigations on the effect of disk roughness, disk lubricant parameters, and air bearing surface design on the friction at the head-disk interface and slider burnishing/wear are conducted and reported.
\end{abstract}

\section{Introduction}

In order to realize higher magnetic storage densities in hard disk drives, it is necessary to reduce and control the read-write head-to-media spacing, or, equivalently, the physical spacing/clearance separating the head from the disk. Current hard disk drive (HDD) products operate with subnanometer clearances using the thermal fly-height control (TFC) technology, where the TFC heater locally deforms the region around the read-write head of the slider bringing it closer to the disk. The head-to-disk clearance can therefore be adjusted by changing the power supplied to the TFC heater.

A touchdown test is used to calibrate the TFC heater power to the clearance. The heater power required to make the head contact the disk lubricant surface, that is, the touchdown power (TDP), is first determined, and the heater power is then reduced to retract the head away from the disk in order to achieve a target clearance. Accurate TDP detection is therefore a key enabling step to using the TFC technology. Inaccurate TDP detection can severely compromise the drive performance: if the actual clearance is too high, the recording performance suffers, and if the actual clearance is too low, it increases the probability for head-disk contact, which leads to unwanted head wear, thus compromising drive reliability.

Research studies on the slider-disk contact interactions and the resulting slider vibrations have been of interest to the HDD community for a long time. Research investigations on the traditional (non-TFC) slider dynamics were motivated by the need to design low flying sliders while mitigating the contact-induced slider vibrations and slider-lubricant interactions, and extensive literature exists on these topics [1-8]. After the introduction of TFC sliders, several researchers have tried to understand and explain the contact and touchdown behavior of TFC sliders owing to its importance in HDD spacing calibration. It has been shown through experiments and simulation that in addition to the slider air bearing surface (ABS) design the disk lubricant and suspension design play an important role in the slider touchdown process [9]. Numerical and analytical simulations accounting for the nonlinear forces at the head-disk interface (HDI) have also successfully explained the strong vibration dynamics of 
the slider close to the TDP and the subsequent suppression of vibrations for powers higher than the TDP [10-12], and they qualitatively support the experimental results reported for certain ABS designs [12, 13]. A full understanding of the touchdown behavior of TFC sliders is still lacking, and it continues to be an active topic of research.

In this work, acoustic emission (AE) sensors and laser doppler vibrometers (LDVs) are used in spin stand experiments focused on touchdown detection and slider dynamics studies. The similarities and differences in the touchdown signature for different slider ABS designs are highlighted. Parametric investigations are conducted to explain the dependence of friction and head wear on disk roughness and lubrication condition. In conjunction with recent work on the interactions of TFC sliders with the disk lubricant during touchdown/contact $[14,15]$, these results help develop a better understanding of the touchdown process of TFC sliders and the complex interactions at the HDI.

\section{Experiments}

Experiments are conducted on a spin stand equipped with an AE sensor to detect contact and an LDV to detect vertical flexure motions of the head gimbal assembly. Three different ABS designs mounted on the same suspension are used in this study. The TDP (i.e., power required to achieve zero clearance or contact with the disk lubricant) is determined experimentally by supplying the TFC heater with a square pulse lasting $70 \mathrm{~ms}$ with increasing power. The AE signal standard deviation is monitored during each power pulse, and the power at which the AE signal standard deviation crosses a specified threshold (set to be $20 \%$ above baseline) is recorded as the TDP.

\section{Results and Discussion}

3.1. Touchdown Behavior/Characteristics. The touchdown plots for three different ABS designs are shown in Figure 1 where ABS-3 shows a favorable "sharp touchdown" while ABS-1 shows an unfavorable "gradual touchdown," and has a slow rise in AE signal for increasing TFC power. ABS-2 has touchdown performance which falls between ABS-1 and ABS-3. A sharp touchdown behavior is preferred as it gives a well-defined estimate of the exact power at which contact with the disk lubricant is achieved.

The sharp touchdown for ABS-3 is characterized by strong individual spikes in the time history of the AE signal while the gradual touchdown for ABS-1 shows a uniformly increased AE signal during the TFC pulse as shown in Figure 2. (The AE signal on these plots have been shifted by $1 \mathrm{~V}$ to show them clearly.)

In addition, tests in overpush (i.e., TFC power above the TDP) reveal that ABS-3 with "sharp touchdown" shows an "overshoot behavior" with very strong AE signal at powers slightly above the TDP and a subsequent suppression of AE signal when the power increases into overpush as seen in Figure 3. In contrast, ABS-1 with the "gradual touchdown" shows no "overshoot" behavior but a gradual increase in

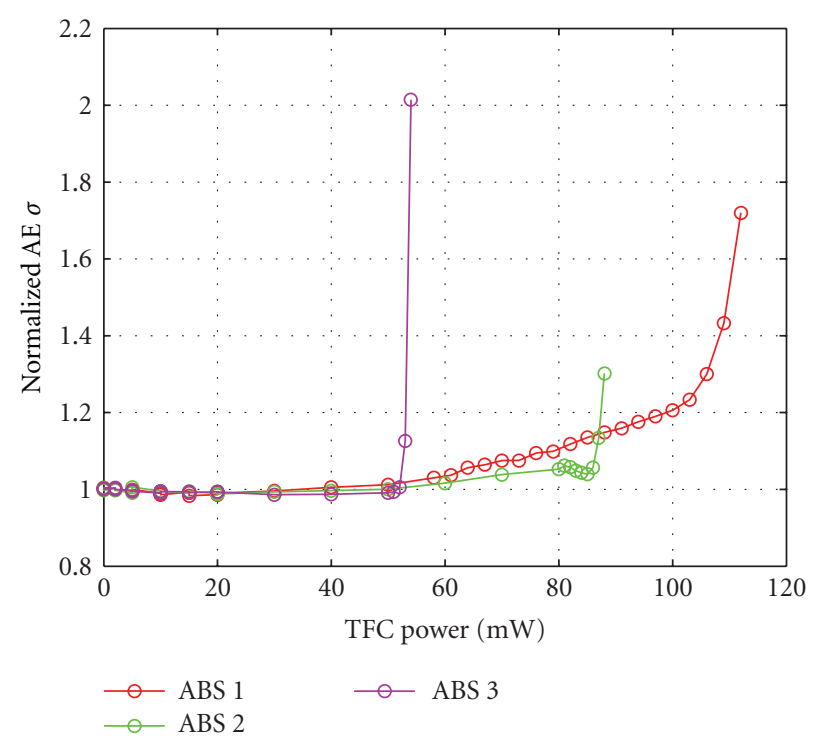

Figure 1: Touchdown plots for the three different ABS designs.

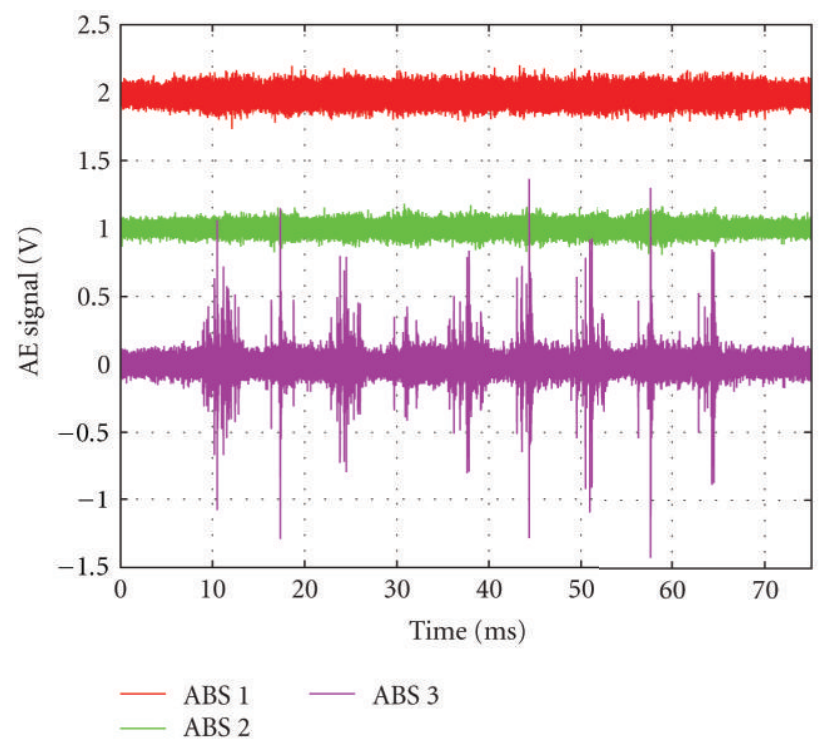

FIGURE 2: Touchdown signature for the three different ABS designs (plots offset by $1 \mathrm{~V}$ for clarity).

AE detected contact with overpush. ABS-2 has behavior in between those of ABS-3 and ABS-1.

Simulations for these three ABS designs show that the increasing sharpness of touchdown correlates with decreasing pressure under the TFC protrusion at touchdown, increased TFC efficiency, and lower TDP (Table 1). It is also observed that lubricant pickup is higher for ABS-3 compared to ABS- 2 or ABS- 1 .

While an explanation of the physical mechanism behind the different ABS touchdown signatures requires a further comprehensive study, important correlations may be drawn from these results. The strong individual spikes for ABS3 are evidence of a snap-in/snap-out behavior, which is an indication of the spontaneous instability of the slider 


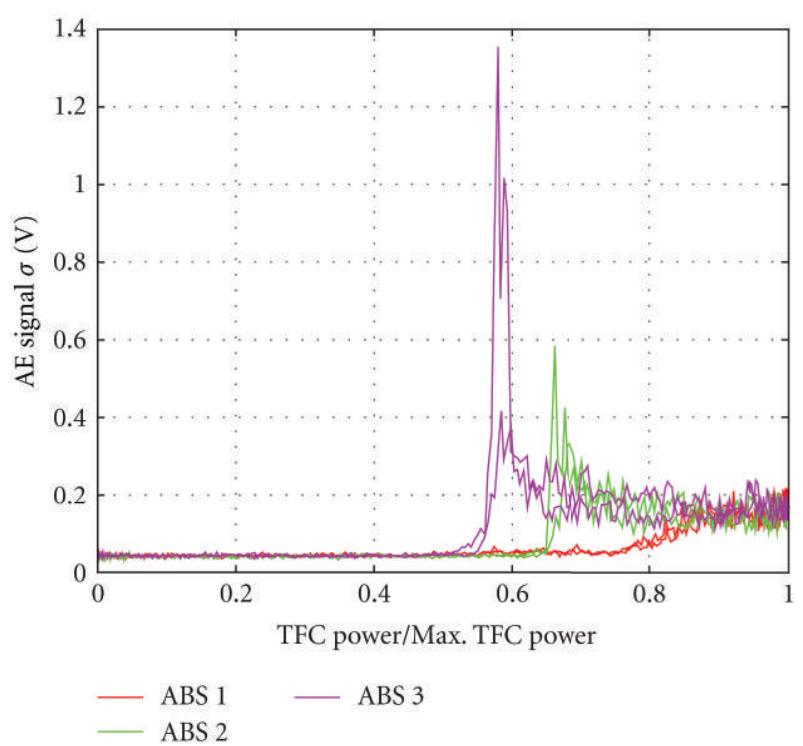

FIGURe 3: Contact behavior in overpush for the three different ABS designs.

TABLE 1: Simulated results for the three different ABS designs.

\begin{tabular}{lccc}
\hline ABS design & $\begin{array}{c}\text { Simulation TFC } \\
\text { efficiency } \\
\mathrm{nm} / \mathrm{mW}\end{array}$ & $\begin{array}{c}\text { Touchdown power } \\
\mathrm{mW}\end{array}$ & $\begin{array}{c}\text { Pressure at } \\
\text { touchdown } \\
\text { atm. }\end{array}$ \\
\hline ABS-1 & 0.108 & 96 & 60 \\
ABS-2 & 0.119 & 91 & 38 \\
ABS-3 & 0.145 & 69 & 27 \\
\hline
\end{tabular}

during touchdown. It is highlighted that the circumferential locations of the spikes do not remain fixed upon repetition of the touchdown test and hence are not caused by disk defects as such. The snap-in/snap-out process causes a higher level of head-disk lubricant interaction, which correlates well with the higher amount of lubricant pickup for ABS-3. It may also be reasoned that the lower pressure at the TFC bulge for ABS-3 makes it more susceptible for lubricant transfer from disk to the slider in comparison to ABS designs with higher pressure at the TFC bulge, such as ABS-1 and ABS-2.

3.2. Analogous Experimental Results. A separate set of experiments with ABS-2 reveals that the touchdown can be sharp or gradual depending on the disk RPM (or the linear velocity) as shown in Figure 4. Specifically, a lower disk RPM increases the touchdown sharpness and a higher disk RPM degrades the touchdown sharpness. It is also observed that the touchdown performance degrades for a burnished slider (as shown by the dashed lines in Figure 4), where the slider is burnished in a controlled fashion by increasing the TFC power above the TDP on a separate disk track. The results for the 7200 RPM case on Figure 4 highlight the possibility of false TDP detection: for the same $20 \%$ AE threshold, the unburnished case shows a gradual AE rise until about $95 \mathrm{~mW}$, but the sharp AE rise at $102 \mathrm{~mW}$ is the actual TDP.
However, the burnished case reads a false TDP at $93 \mathrm{~mW}$ owing to the gradual rise in $\mathrm{AE}$ that occurs before the sharp $\mathrm{AE}$ rise marking touchdown. The time history of the $\mathrm{AE}$ signal is similar to that observed with the different ABS designs; namely, strong individual AE spikes appear for the 3600 RPM case with sharp touchdown, and a uniformly increased AE signal appears for the 7200 RPM case with gradual touchdown (Figure 5). These analogous results for ABS-2 provide a way to probe the same HDI under different disk RPM to understand the changes that occur in the AE and LDV signals for "sharp" and "gradual" touchdown signatures as well as in overpush.

3.3. LDV Spectrum and AE Signal Content. Experiments are conducted with ABS-2 to simultaneously capture the $\mathrm{AE}$ signal and the LDV signal in order to identify the frequencies that correspond to the flexure and slider vertical motions and to see how they appear in the AE signal. The tests are conducted with the power increased above the TDP (i.e., into overpush). For this ABS-2 design, the simulated air bearing frequencies at $5400 \mathrm{RPM}$ and $1 \mathrm{~nm}$ minimum spacing are $142 \mathrm{kHz}$ (roll), $167 \mathrm{kHz}$ (pitch-1), and $324 \mathrm{kHz}$ (pitch-2).

For each of the overpush tests conducted at different RPM, Figure 6 shows the profile of the applied TFC voltage and the time history of the LDV signal on one plot, and the corresponding joint time frequency spectrum of the LDV signal on a separate plot. As seen on the figures, the TFC voltage increases from zero to the target overpush value (between $50 \mathrm{~ms}$ to $100 \mathrm{~ms}$ ), remains at this value (between $100 \mathrm{~ms}$ to $200 \mathrm{~ms}$ ), and decreases back to zero (between $200 \mathrm{~ms}$ to $250 \mathrm{~ms}$ ). During the overpush regime, the slider vibrations are excited due to contact, and the dominant excitation frequencies are identified on the plots showing the joint time frequency spectrum. It is observed that for 3600 RPM the lower frequencies (notably 139, 148, and $165 \mathrm{kHz}$ which are close to simulated roll and pitch-1 air bearing frequencies) are dominant, while for the 7200 RPM the higher air bearing frequency $321 \mathrm{kHz}$ (corresponding to pitch-2 air bearing frequency) is dominant. This result indicates that the mechanism/nature of touchdown and contact at the HDI is significantly altered by the disk RPM. Specifically in this case, the excited vibration modes at contact are shifted from the lower frequency pitch- 1 and roll modes at lower disk RPM, to the higher frequency pitch-2 modes at higher disk RPM. The pitch-1 nodal line passes through the trailing end of the slider, and its excitation in general is associated with stronger motions of the entire slider body. Such excitation may, in fact, be responsible for the stronger "sharp touchdown" signature. In contrast, the pitch-2 nodal line lies closer to the leading end of the slider, and its excitation only causes the vertical bouncing motion of the trailing end, resulting only in localized contact at the TFC bulge location, and, therefore, leading to the weaker "gradual touchdown" signature. It is surmised that, in an analogous fashion, the touchdown process excites different vibrations modes for the three different ABS designs presented in Section 3.1, hence causing the very different sensitivities at touchdown. 


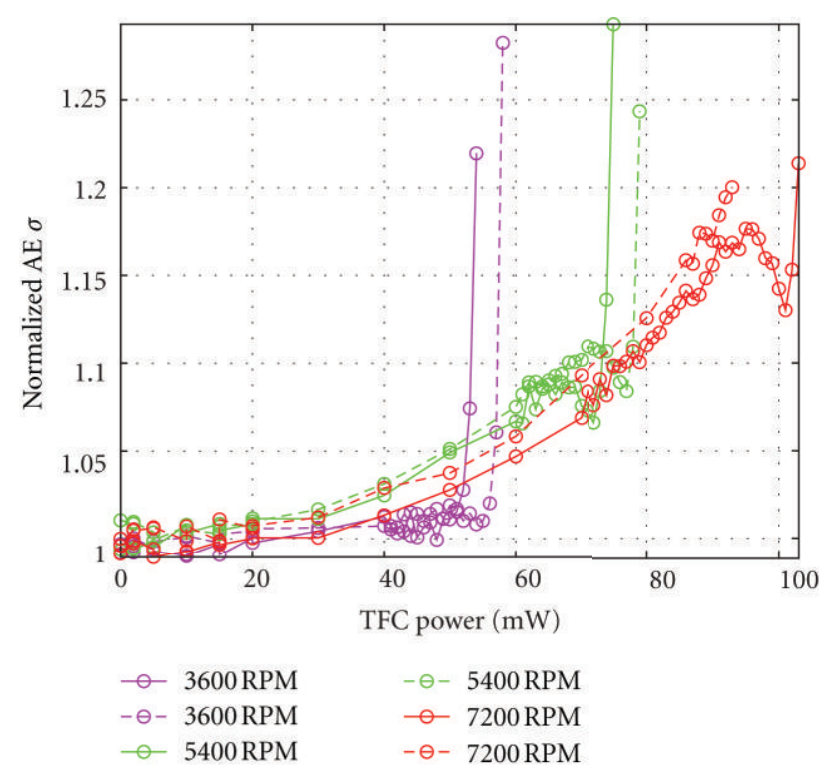

FIgUre 4: Touchdown plots for ABS-2 at different disk RPM (dashed lines for a burnished slider).

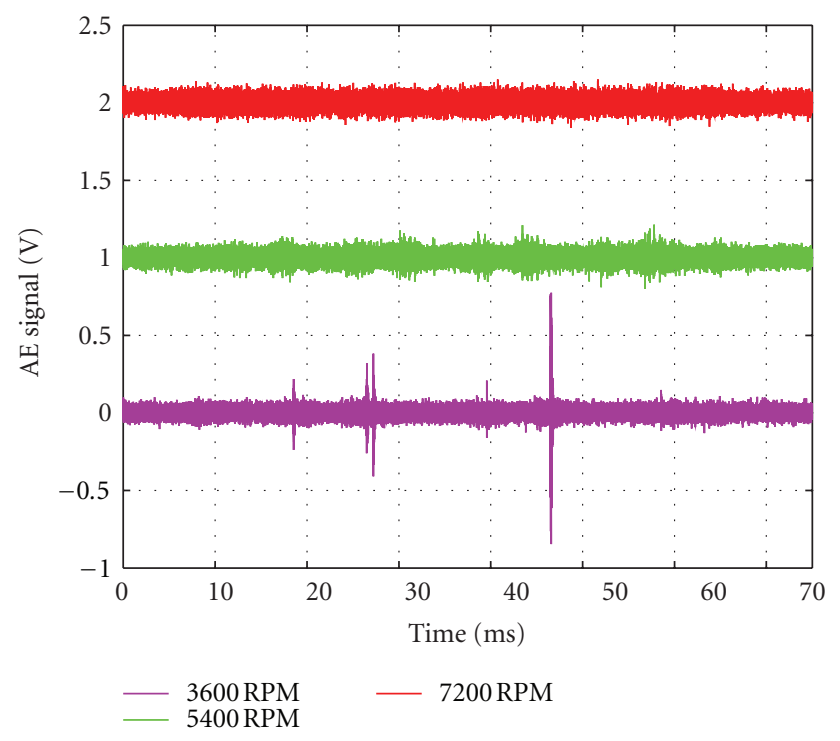

Figure 5: Touchdown signature for ABS-2 at different disk RPM (plots offset by $1 \mathrm{~V}$ for clarity).

The components of the AE signal at the different frequencies observed in the LDV signal are plotted in Figure 7 to observe how they change as a function of the TFC power. (The cumulative effect of adding all these components would result in the plot shown in Figure 4.) At 3600 RPM the touchdown is marked by the sharp rise in the $148 \mathrm{kHz}$ component and there are no components that show gradual rise. At $5400 \mathrm{RPM}$, the $148 \mathrm{kHz}$ component shows a gradual rise, but touchdown is marked by a sharp rise in the $321 \mathrm{kHz}$ component. At 7200 RPM, there are no components with a sharp rise, and the $321 \mathrm{kHz}$ component shows a gradual rise.
These results indicate that at $3600 \mathrm{RPM}$ the contact is dominated by the slider's pitch-1 and roll motions (together with any suspension-related motions that give rise to frequency peaks in the $65-100 \mathrm{kHz}$ region.) At $7200 \mathrm{RPM}$, contact is mainly dominated by the vibration of the slider at the pitch-2 frequency. At $5400 \mathrm{RPM}$, the interaction is a combination of the above two modes: as the TFC powers increase, a gradual rise in the $148 \mathrm{kHz}$ component occurs first, but a strong vibration in the pitch-2 mode $(321 \mathrm{kHz})$ eventually marks touchdown.

These results are in agreement with recent studies that show that at close spacing and at the onset of lubricantcontact, the in-plane shear forces and friction can destabilize the slider for certain ABS designs resulting in vibrations dominantly occurring at suspension and lower air bearing frequencies $(60-200 \mathrm{kHz}$ in our case), while stronger contact with the disk causes slider vibrations with higher frequency content (above $200 \mathrm{kHz}$ ) [9].

3.4. Friction Measurements in Contact. Friction forces at the HDI become important during contact conditions and may in fact play a dominant role in HDI performance and slider dynamics. Friction-induced slider wear, as well as disk lubricant redistribution and disk overcoat damage, needs to be examined carefully to explore future designs that can accommodate a certain level of head-disk contact.

Experiments are devised to measure the friction forces in the downtrack direction during contact and overpush conditions by instrumenting a strain gage on the fixture which holds the head gimbal assembly on the spin stand. The voltage signal from the strain gage may be converted into force measurement by determining the calibration constant for the strain gage. Such a calibration is performed using the usual technique: by noting the strain gage voltage signal corresponding to different standard forces, which are applied by suspending standard weights from the fixture, and subsequently fitting a linear curve.

Once the TDP is determined on the test track, the TFC is powered with a voltage profile having $100 \mathrm{~ms}$ dwell time at the maximum power. It is noted that strain gages have a low bandwidth, and several experiments reveal that a dwell time of at least $100 \mathrm{~ms}$ is necessary to allow the strain gage to respond to the friction force and give good, repeatable measurements. All experiments are conducted with ABS-2 on a reference "standard disk" unless specified otherwise.

3.4.1. Friction, $A E$, and Slider Bouncing in Contact. Figures $8(\mathrm{a})$ and $8(\mathrm{~b})$ show the TFC voltage profile and the resulting slider bouncing (displacement and velocity), AE detected contact, and the friction force, for $10 \mathrm{~mW}$ and $20 \mathrm{~mW}$ overpush, respectively. It is evident that slider bouncing and $\mathrm{AE}$ signal remain high throughout the overpush region for $10 \mathrm{~mW}$ overpush case, and they get suppressed (after an initial overshoot region) for the $20 \mathrm{~mW}$ overpush case. The friction force measured by the strain gage, however, continues to increase with the amount of overpush indicating a higher level of interference and contact for larger overpush powers even though the $\mathrm{AE}$ detected contact and slider 


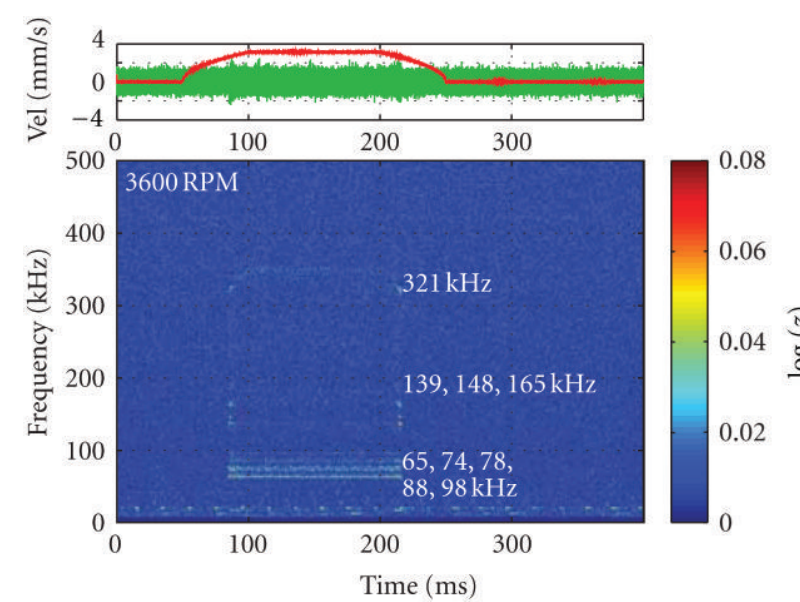

(a)

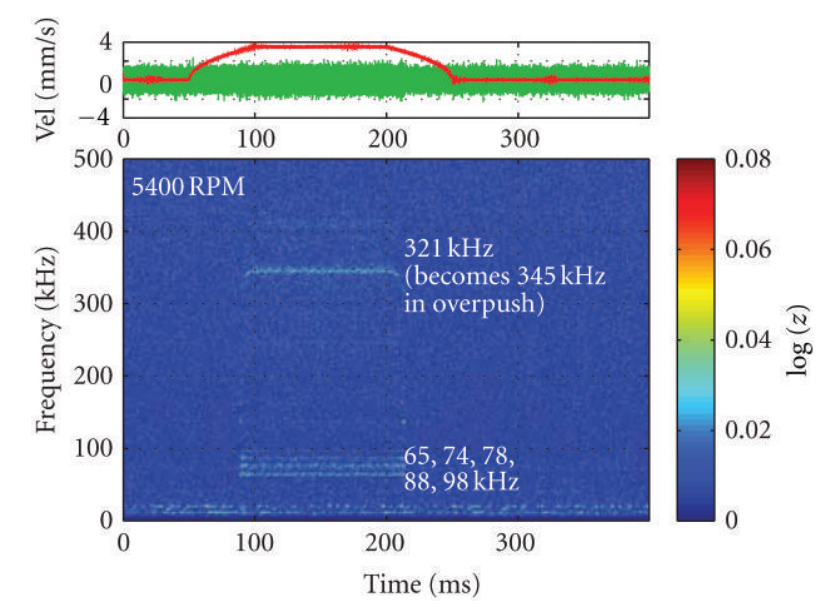

(b)

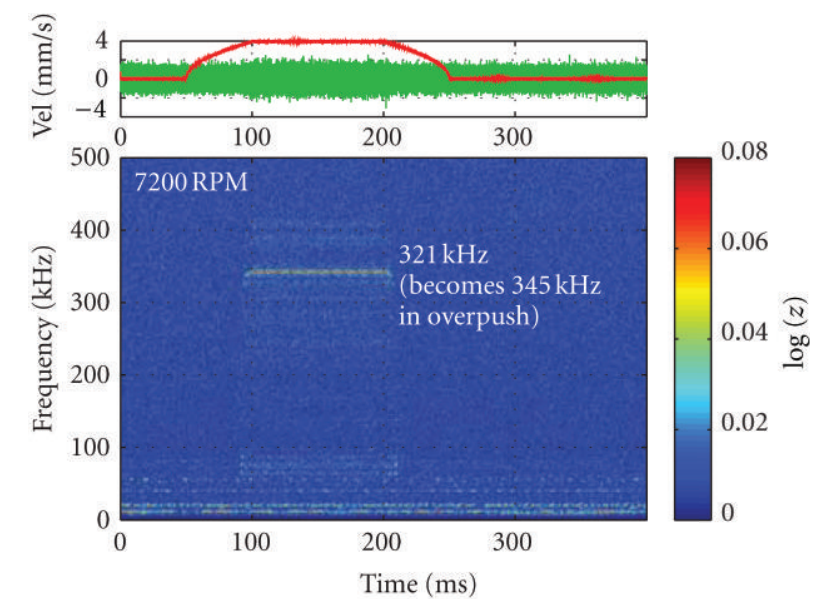

(c)

FIGURE 6: Applied TFC voltage profile, vertical velocity time history, and the joint time frequency spectrum of the vertical velocity for ABS-2 at different disk RPM.

dynamics get suppressed. (It is noted that the amplitude of the AE signal in the suppressed state is noticeably higher than the baseline AE signal with no TFC power, implying a certain amount of contact).

3.4.2. Effect of Disk Roughness. Disk roughness plays an important role in HDI performance. The combined slider and disk roughness affect the nominal physical spacing at the HDI, the magnitude of interaction forces (intermolecular/adhesive, etc.), and the actual area of contact, thereby influencing the magnitude of contact and friction forces. A parametric study is conducted with three disk types: disks A, $\mathrm{B}$, and $\mathrm{C}$ with decreasing roughness, in that order, and with surface roughness parameters tabulated in Table 2, where $R_{q}$ is the root mean square roughness, $R_{p}$ is the maximum peak height, and $R_{v}$ is the maximum valley depth. These disks are coated with ZTMD lubricant of nominal 12 A thickness.

First, several tests are conducted using the same slider to determine the TDP on a standard disk and on each of the disks A, B, and C. Table 2 presents the change in the TDP (i.e., $\delta \mathrm{TDP}$ ) on each of the disks A, B, and C compared to the TDP on a standard disk. The roughness of the standard disk is similar to that of disk A. This difference in TDP is converted into a clearance gain value (i.e. a gain in clearance from that on a standard disk) using a conversion factor of $0.119 \mathrm{~nm} / \mathrm{mW}$, which is the TFC efficiency estimated for ABS-2 from simulations. Figure 9 shows the same information in graphical form and highlights the linear relationship between the disk roughness $\left(R_{p}\right.$ or $R_{q}$ ) and clearance gain. Since the thermal protrusion comes into contact with the peaks of the roughness, the relationship between the clearance gain and $R_{p}$ (Figure 9(b)) is of importance, and it is seen that for every $1 \mathrm{~nm}$ decrease in $R_{p}$ there is a $0.8 \mathrm{~nm}$ actual gain in clearance at the HDI for the range of surface roughness values considered in these experiments.

Next, the dependence of friction on the disk roughness is investigated by conducting a "friction test" on each of the three disk types. A new (unburnished) slider is flown on a fresh test track, the TDP is determined, and the TFC heater is then supplied with the power profile with a $100 \mathrm{~ms}$ 


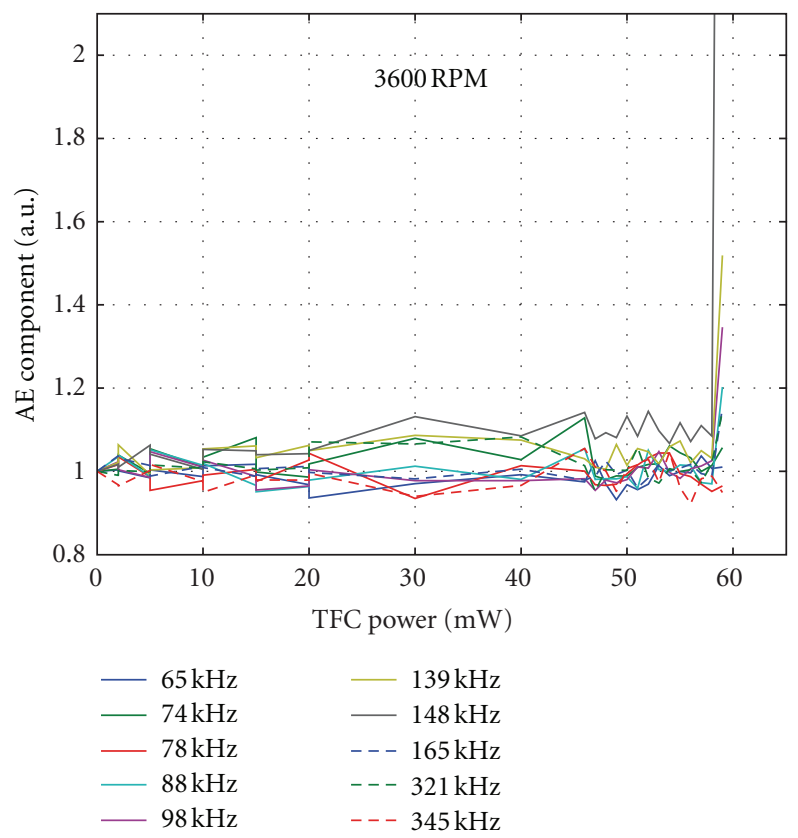

(a)

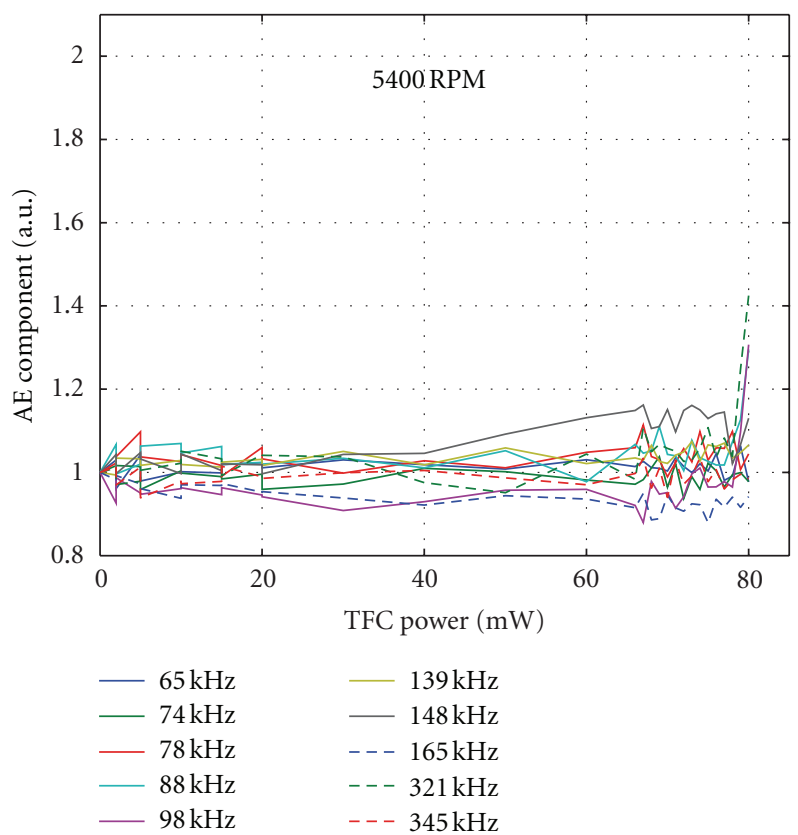

(b)

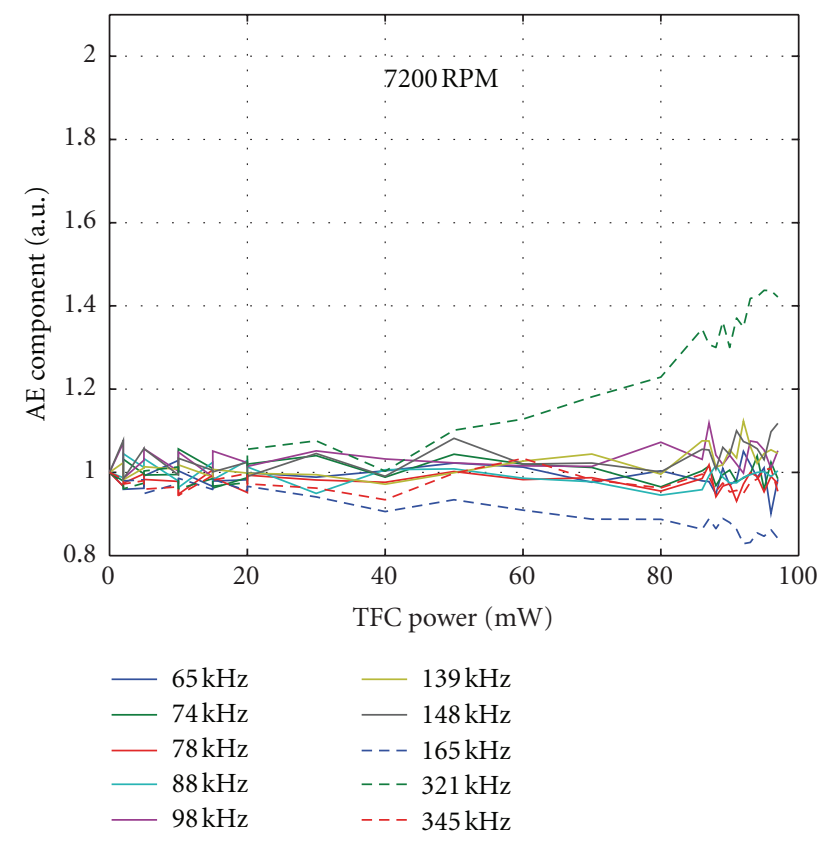

(c)

FIGURE 7: AE signal components in the touchdown plot for ABS-2 at different disk RPM.

dwell time (as shown in Figure 8). The peak TFC power is increased from TDP to a maximum of TDP $+50 \mathrm{~mW}$ in $5 \mathrm{~mW}$ increments, and it is then similarly decreased back to TDP. The average friction measured by the strain gage at each power step is tabulated. All tests are conducted on the same disk track. The measured friction values are plotted as those for the "unburnished" case. The same slider, which is now deemed "burnished" because of the overpush testing, is flown on an adjacent track and the friction test is repeated to obtain friction values for the "burnished" case. Figure 10(a) shows a representative plot for the strain gage measured friction values as a function of overpush power supplied to the TFC heater.

A quadratic curve passing through the origin is fit to the friction measurements for the "unburnished" and "burnished" cases, and the slope of this curve at the $10 \mathrm{~mW}$ overpush point is used to obtain the "friction $(\mu \mathrm{N})$ per milliwatt of overpush power" value. Figure 10(b) plots these friction values measured on the three disk types (A, B, and C) based on experiments conducted with three new sliders 
TABLE 2: Disk roughness parameters and its effect on TDP/clearance gain.

\begin{tabular}{lccccc}
\hline Disk & $\begin{array}{c}R_{p} \\
\mathrm{~nm}\end{array}$ & $\begin{array}{c}R_{q} \\
\mathrm{~nm}\end{array}$ & $\begin{array}{c}R_{v} \\
\mathrm{~nm}\end{array}$ & $\begin{array}{c}\delta \mathrm{TDP} \\
\mathrm{mW}\end{array}$ & $\begin{array}{c}\text { Clearance gain } \\
\mathrm{nm}\end{array}$ \\
\hline $\mathrm{A}$ & 2.02 & 0.49 & 1.87 & 0.08 & 0.01 \\
$\mathrm{~B}$ & 1.89 & 0.36 & 1.47 & 0.97 & 0.12 \\
$\mathrm{C}$ & 1.00 & 0.24 & 1.11 & 6.71 & 0.84 \\
\hline
\end{tabular}

on each disk type. While there is no particular trend relating the measured friction and surface roughness, the friction is higher for the burnished slider compared to the unburnished slider in all tests. Slider burnishing wears and smoothens the slider surface, increasing the actual contact area between the thermal protrusion and the disk, thereby resulting in the slightly higher friction force.

In order to directly compare the friction values between the three disk types, another set of experiments is conducted by flying the same "burnished" slider on the three disk types in succession. The slider is burnished in a controlled fashion separately before use in this test. The friction against the overpush power is plotted in Figure 10(c) using data from two "burnished" heads. It is concluded based on these results that within the range of disk roughness considered in this work there is no significant effect of the disk surface roughness on the measured friction.

3.4.3. Effect of Lubricant Parameters. Friction tests are conducted to determine the effect of lubricant type/bonding on the friction in contact. Disks with three different lubricant type/bonding ratios are used: Lube A (61\% bonded ratio, $10.5 \AA$ ), Lube A (69\% bonded, $10.5 \AA)$, and Lube B ( $82 \%$ bonded, $12 \AA$ ). Figure 11(a) shows the friction measured for the three media for the "unburnished" and "burnished" slider cases (based on three experiments each). The friction values are comparable for the unburnished sliders on all three disks types. While the friction values for the burnished and unburnished sliders are comparable on the disks with Lube A $61 \%$ and $69 \%$ bonded ratio, the friction for the burnished slider on the disk with Lube B $82 \%$ bonded ratio is relatively higher than that for the unburnished slider. This result is consistent with results for the change in TDP occurring because of a friction test, where the TDP change after and before a friction test is a measure of slider burnishing. As shown in Figure 11(b), the highest burnishing (indicated by highest $\delta$ TDP) occurs to a new "unburnished" slider on the Lube B $82 \%$ bonded disk. As a result of greater slider burnishing on this disk, the friction is higher when a subsequent test is conducted with this burnished slider.

A direct comparison of friction values is reported in Figure 11(c) based on tests conducted in succession on the three different disks using two "burnished" sliders, and it shows marginally higher friction values on the disk with Lube B $82 \%$ bonded ratio.

Friction tests are conducted to understand the effect of the mobile part of the lubricant on friction and slider burnishing. The disk with Lube A $10.5 \AA 61 \%$ bonded fraction is delubed by immersing it in a solution of Vertrel XF solution
TABLE 3: Effect of TFC efficiency (ABS/heater design) on friction.

\begin{tabular}{lccc}
\hline ABS design & $\begin{array}{c}\text { Simulation TFC } \\
\text { efficiency } \\
\mathrm{nm} / \mathrm{mW}\end{array}$ & $\begin{array}{c}\text { Friction } \\
\text { unburnished } \\
\mu \mathrm{N} / \mathrm{mW}\end{array}$ & $\begin{array}{c}\text { Friction } \\
\text { burnished } \\
\mu \mathrm{N} / \mathrm{mW}\end{array}$ \\
\hline ABS-A (ABS-1) & 0.108 & 9 & 17 \\
ABS-B & 0.111 & 24 & 31 \\
ABS-C (ABS-2) & 0.119 & 37 & 54 \\
ABS-D (ABS-3) & 0.145 & 56 & 67 \\
\hline
\end{tabular}

to remove the mobile lubricant. The delubed disk has a lubricant thickness of $6 \AA$ (bonded lubricant). Figure 12(a) shows the measured friction on the lubed and delubed disks for the unburnished and burnished slider cases. The friction values for the unburnished as well as burnished slider on the lubed disk are similar and comparable to the friction value measured for the unburnished slider on the delubed disk. However, the friction is substantially higher for the burnished slider on the delubed disk. Figure 12(b) shows that slider burnishing (indicated by $\delta$ TDP after a friction test) is higher for tests conducted on the delubed disk implying that an unburnished slider is substantially burnished on this disk type, and the friction is higher for the subsequent test conducted with such a burnished slider. These results highlight the important role of the mobile part of the lubricant in reducing friction and slider burnishing, thereby increasing the reliability of an HDI with contact.

3.4.4. Effect of TFC Efficiency. The thermal protrusion size and shape make a significant difference in the slider's touchdown and contact behavior. The friction during contact for different slider ABS/heater designs is plotted in Figure 13 for the unburnished and burnished cases, and the same data is tabulated in Table 3 together with each design's TFC efficiency estimated from simulations. It is observed that the friction forces increase as the TFC efficiency increases and may be explained by the following argument. For the same amount of overpush power, a higher TFC efficiency slider will have greater level of interference (because of a larger protrusion). As a result, the effective contact area is larger for the higher TFC efficiency case, reflecting in a higher measured friction.

3.4.5. Effect of Disk RPM. The similarities between the touchdown plot and contact signature of ABS-2 at different disk RPMs to those of ABS designs with different TFC efficiencies are highlighted in Section 3.2. Particularly, it is shown that at a higher RPM ABS-2 behaves like a design with low TFC efficiency (showing a gradual touchdown plot), and at a lower RPM ABS-2 behaves like a design with high TFC efficiency (showing a sharp touchdown plot).

The friction results from tests with ABS-2 at different RPM are consistent with the above analogy and with the results presented in Section 3.4.4. Figure 14 shows that the friction increases as the disk RPM decreases; that is, when ABS-2 is made to behave like a slider with high TFC 


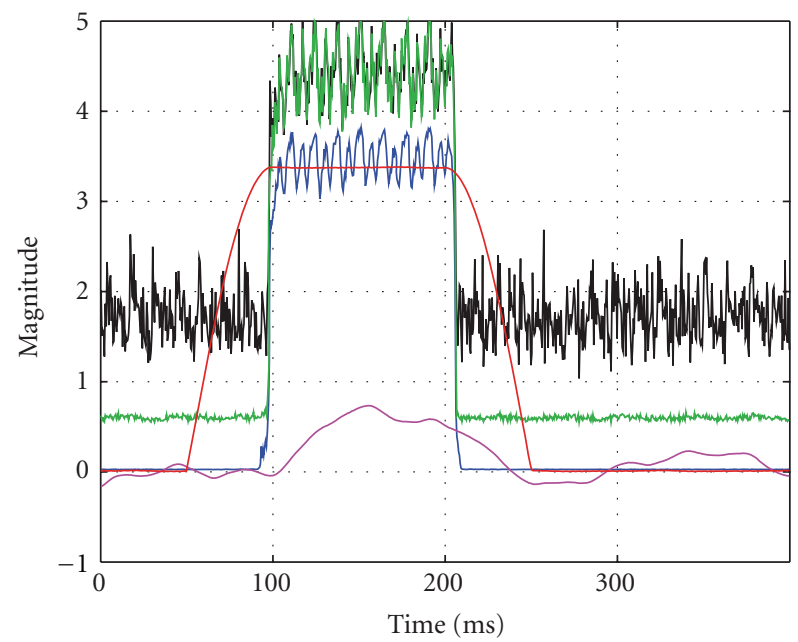

Disp. $\sigma(\mathrm{nm}) \quad$ - Fric. $(\mathrm{mN})$
AE $\sigma(\mathrm{V})$
Vel. $\sigma(\mathrm{mm} / \mathrm{s})$

(a)

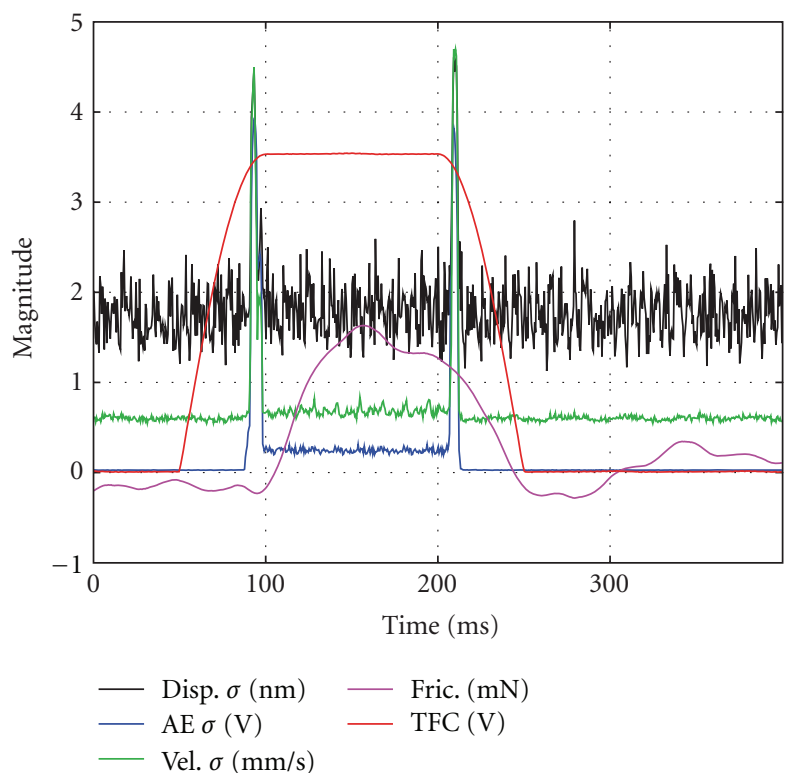

(b)

FIGURE 8: Time history of TFC power, vertical displacement, vertical velocity, AE signal, and friction. (a) $10 \mathrm{~mW}$ overpush, (b) $20 \mathrm{~mW}$ overpush.

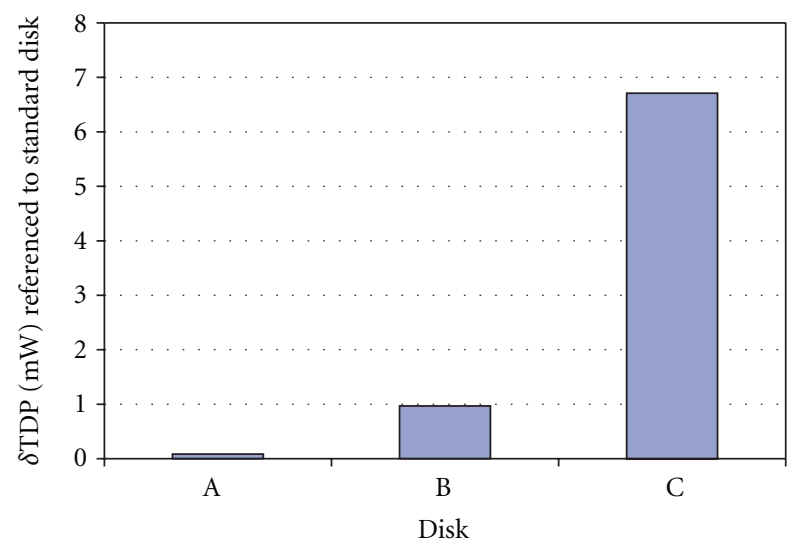

(a)

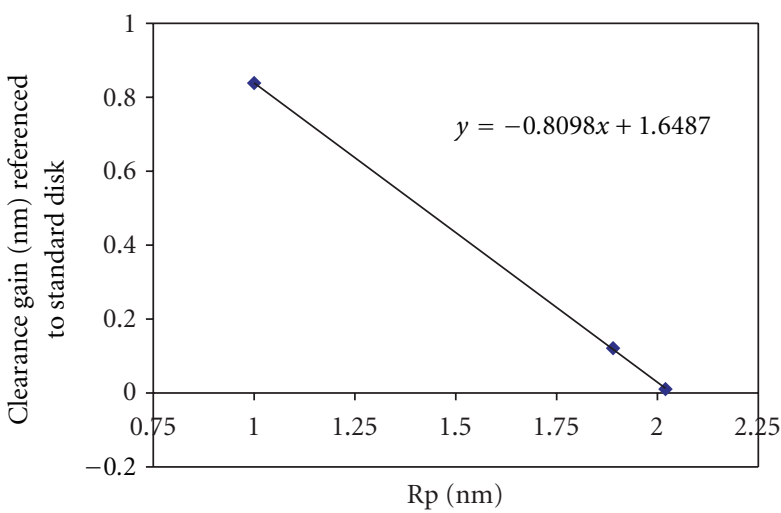

(b)

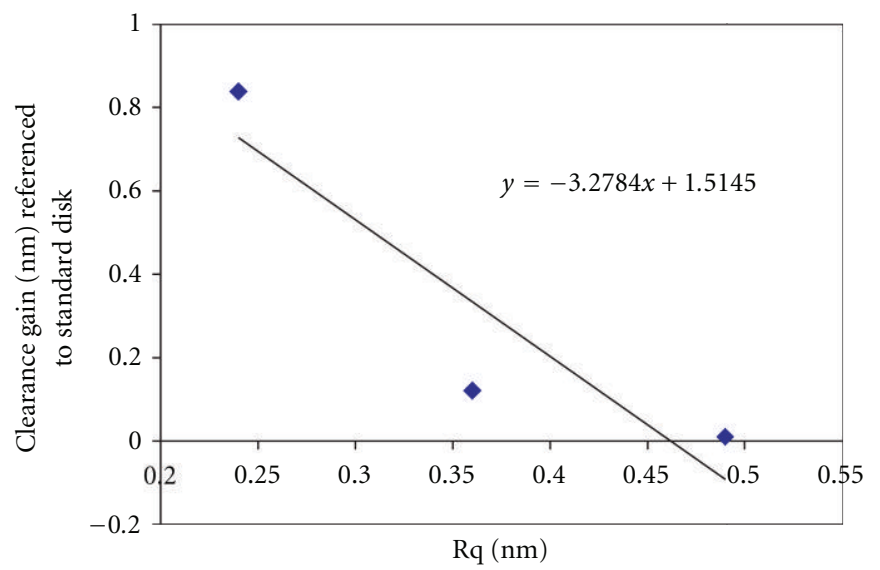

(c)

Figure 9: Effect of disk roughness on clearance. 


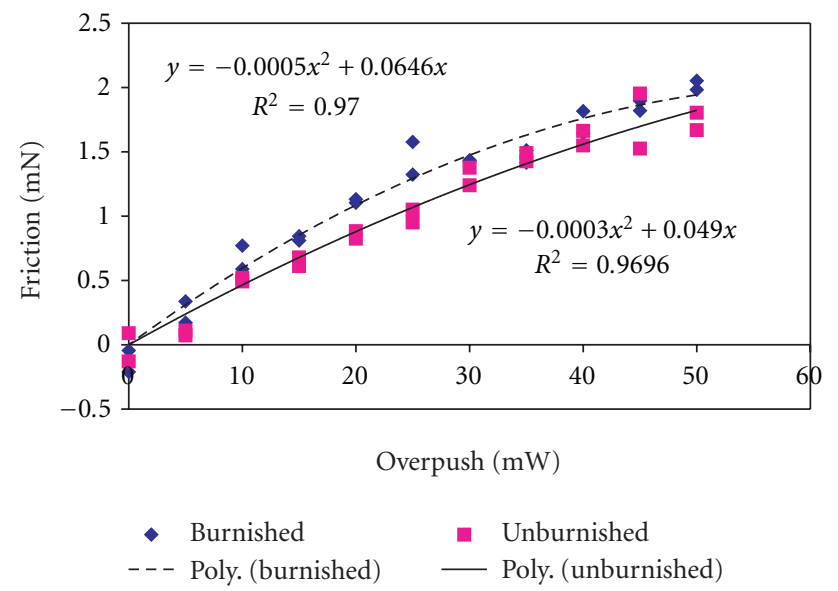

(a)

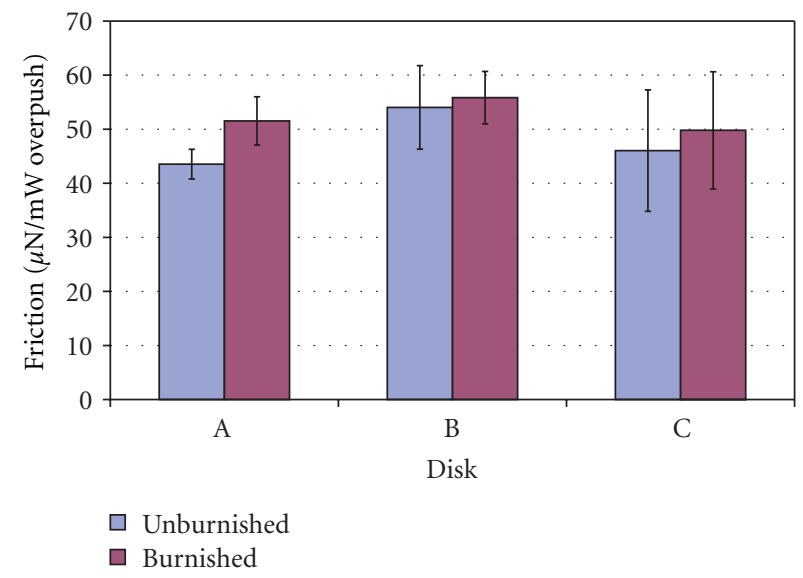

(b)

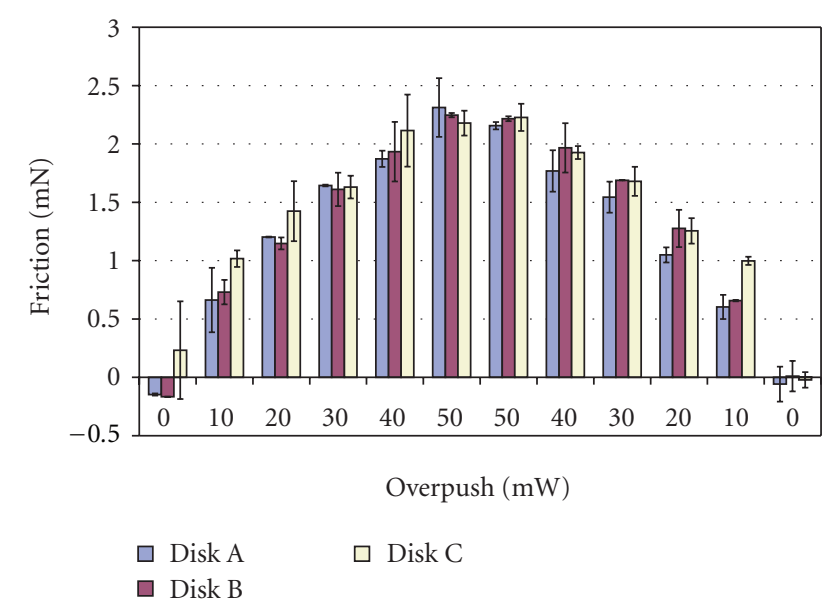

(c)

Figure 10: Effect of disk roughness on friction.

efficiency by decreasing RPM, it exhibits the characteristic sharp touchdown plot and higher friction.

\section{Conclusion}

The touchdown behavior of TFC sliders is investigated through experiments. Certain sliders exhibit a sharp rise of

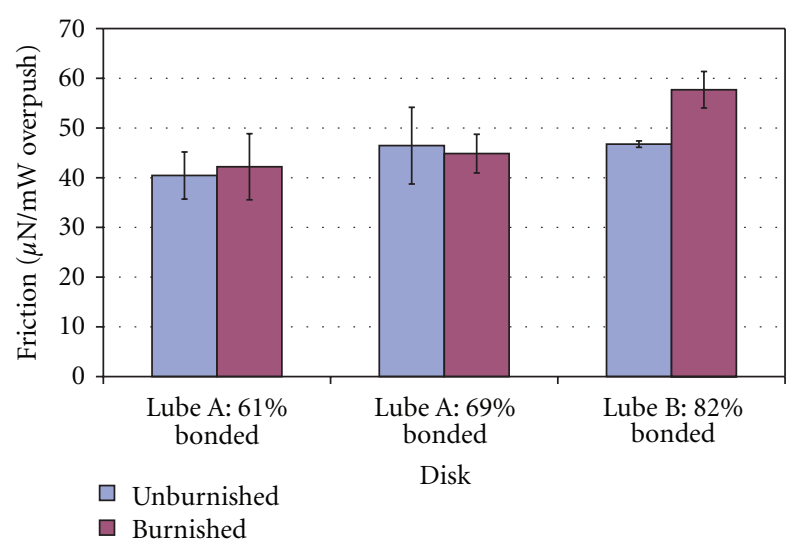

(a)

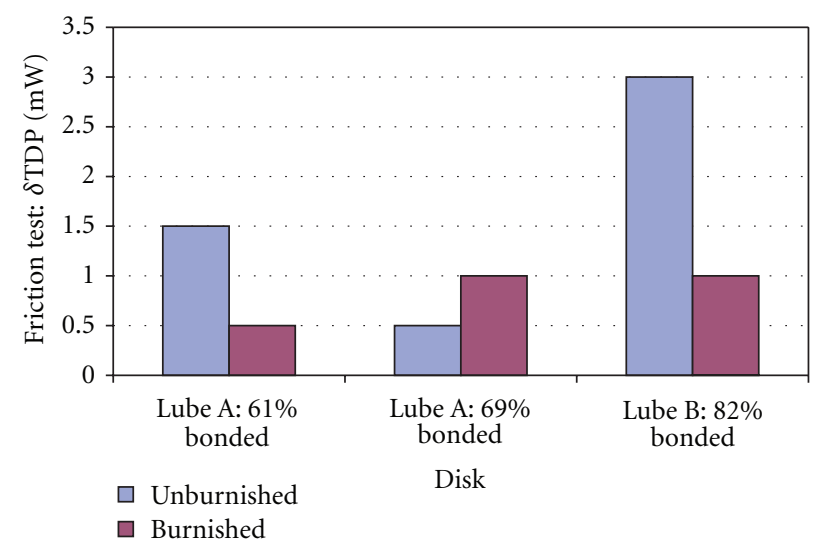

(b)

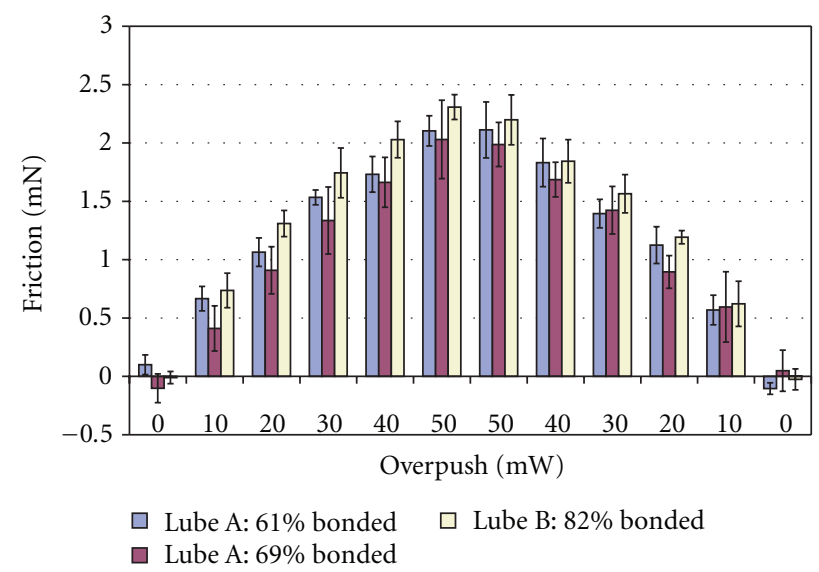

(c)

FIGURE 11: Effect of lubricant parameters on friction and slider burnishing.

AE signal at touchdown when the power is increased in milliwatt steps while others show a gradual rise making it difficult to exactly define the TDP to milliwatt resolution. An analogous behavior occurs when the disk RPM is changed for a particular slider ABS. It is found that the dominant modes/frequencies of excitation at touchdown are significantly different in these cases leading to the very different touchdown signatures. Particularly, the sharp touchdown 


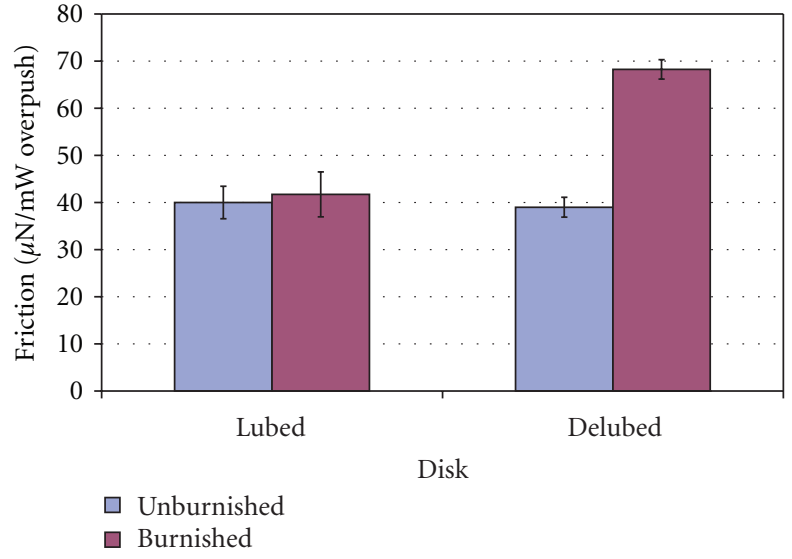

(a)

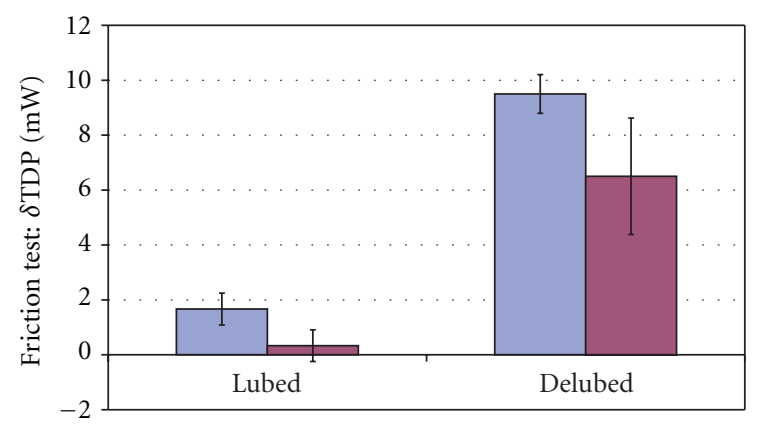

Disk

$\square$ Unburnished

Burnished

(b)

Figure 12: Effect of mobile lubricant on friction and slider burnishing.

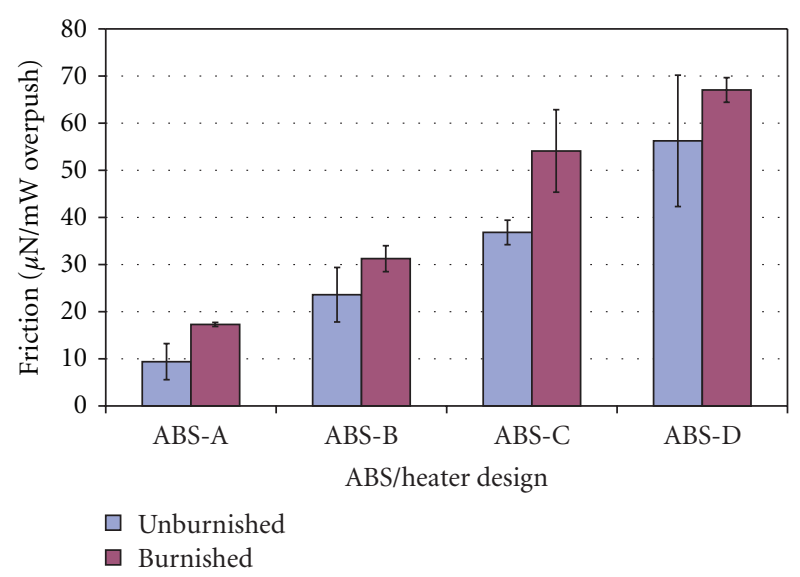

FIGURE 13: Effect of TFC efficiency (ABS/heater design) on friction.

case is characterized by strong individual contact events as observed in the AE signal, and the dominant excitation occurs at frequencies that correspond to the slider's first pitch and roll modes in addition to suspension related-frequencies. In contrast, the gradual touchdown case is characterized by a uniform rise in AE signal over the duration of the TFC

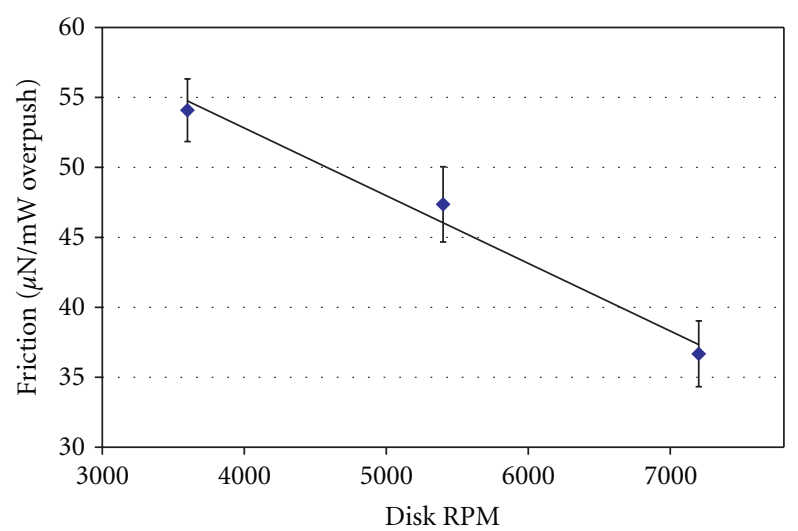

FIGURE 14: Effect of disk RPM on friction for ABS-2.

pulse, and the dominant excitation occurs at the slider's second pitch mode. The pressure under the TFC protrusion at touchdown, the TFC efficiency, and the propensity for lubricant pickup show correlation with touchdown behavior and may be used as metrics for designing sliders with good touchdown features. Experiments are devised to measure the friction at the HDI during TFC-induced contact, and several parametric investigations are carried out. In the range of parameter values considered, the disk surface roughness does not significantly affect the friction during contact. The mobile part of the lubricant plays an important role in reducing friction as well as slider burnishing. A burnished slider shows a higher friction value than an unburnished slider because of an increase in effective/actual contact area, and, for the same reason, sliders with higher TFC efficiency show higher friction compared to sliders with lower TFC efficiency.

\section{Acknowledgments}

This work was supported by the Computer Mechanics Laboratory at the University of California at Berkeley and Hitachi Global Storage Technologies. The authors thank Q. Dai, L. Dorius, XC. Guo, B. Marchon, and R. Waltman for their support and helpful discussions during the course of this work.

\section{References}

[1] B. Knigge and F. E. Talke, "Dynamics of transient events at the head/disk interface," Tribology International, vol. 34, no. 7, pp. 453-460, 2001.

[2] C. M. Mate, P. C. Arnett, P. Baumgart et al., "Dynamics of contacting head-disk interfaces," IEEE Transactions on Magnetics, vol. 40, no. 4, pp. 3156-3158, 2004.

[3] J. Xu, H. Kohira, H. Tanaka, and S. Saegusa, "Partial-contact head-disk interface approach for high-density recording," IEEE Transactions on Magnetics, vol. 41, no. 10, pp. 3031-3033, 2005.

[4] J. D. Kiely and Y. T. Hsia, "Slider dynamic motion during writer-induced head-disk contact," Microsystem Technologies, vol. 14, no. 3, pp. 403-409, 2008.

[5] Q. Dai, B. E. Knigge, R. J. Waltman, and B. Marchon, "Time evolution of lubricant-slider dynamic interactions," 
IEEE Transactions on Magnetics, vol. 39, no. 5, pp. 2459-2461, 2003.

[6] Q. Dai, F. Hendriks, and B. Marchon, "Washboard effect at head-disk interface," IEEE Transactions on Magnetics, vol. 40, no. 4, pp. 3159-3161, 2004.

[7] B. Marchon, X. C. Guo, A. Moser, A. Spool, R. Kroeker, and F. Crimi, "Lubricant dynamics on a slider: 'the waterfall effect', Journal of Applied Physics, vol. 105, no. 7, Article ID 074313, 2009.

[8] C. M. Mate, B. Marchon, A. N. Murthy, and S. H. Kim, "Lubricant-induced spacing increases at slider-disk interfaces in disk drives," Tribology Letters, vol. 37, no. 3, pp. 581-590, 2010.

[9] Q. H. Zeng, C. H. Yang, S. Ka, and E. Cha, "An experimental and simulation study of touchdown dynamics ," IEEE Transactions on Magnetics, vol. 47, pp. 3433-3436, 2011.

[10] J. Zheng and D. B. Bogy, "Investigation of flying-height stability of thermal fly-height control sliders in lubricant or solid contact with roughness," Tribology Letters, vol. 38, no. 3, pp. 283-289, 2010.

[11] J. Zheng and D. Bogy, "Dynamic instability of thermal-flyingheight-control sliders at touchdown," Microsystem Technologies, vol. 18, no. 9-10, pp. 1319-1322, 2012.

[12] S. Vangipuram Canchi and D. B. Bogy, "Thermal fly-height control slider instability and dynamics at touchdown: explanations using nonlinear systems theory," Journal of Tribology, vol. 133, no. 2, Article ID 021902, 2011.

[13] S. Vangipuram Canchi and D. Bogy, "Slider dynamics in the lubricant-contact regime ," IEEE Transactions on Magnetics, vol. 46, pp. 764-769, 2010.

[14] S. Vangipuram Canchi and D. B. Bogy, "Slider-lubricant interactions and lubricant distribution for contact and near contact recording conditions," IEEE Transactions on Magnetics, vol. 47, no. 7, pp. 1842-1848, 2011.

[15] S. Vangipuram Canchi and D. Bogy, "Experiments on slider lubricant interactions and lubricant transfer using TFC sliders," Microsystem Technologies, vol. 18, pp. 1517-1523, 2012. 

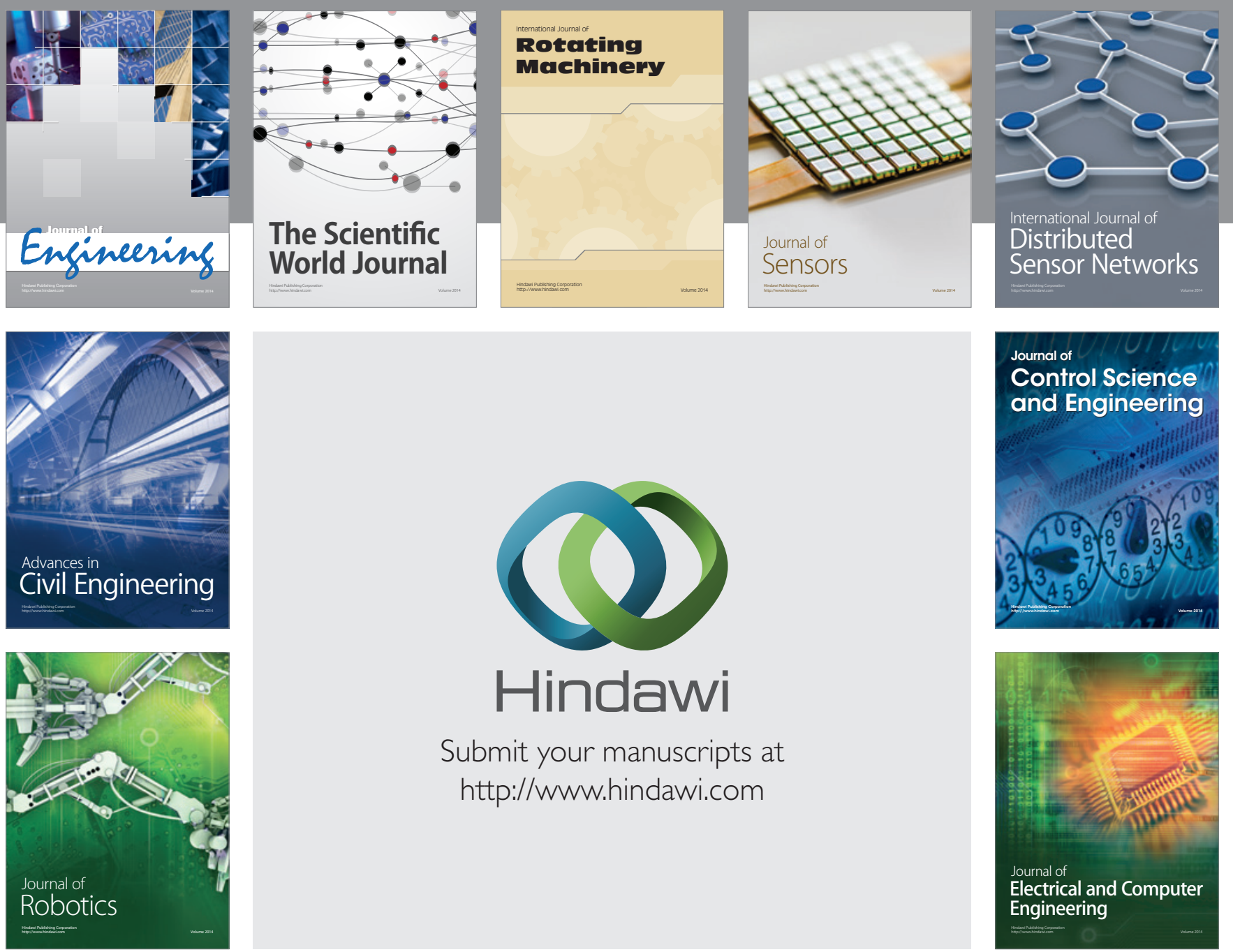

Submit your manuscripts at

http://www.hindawi.com
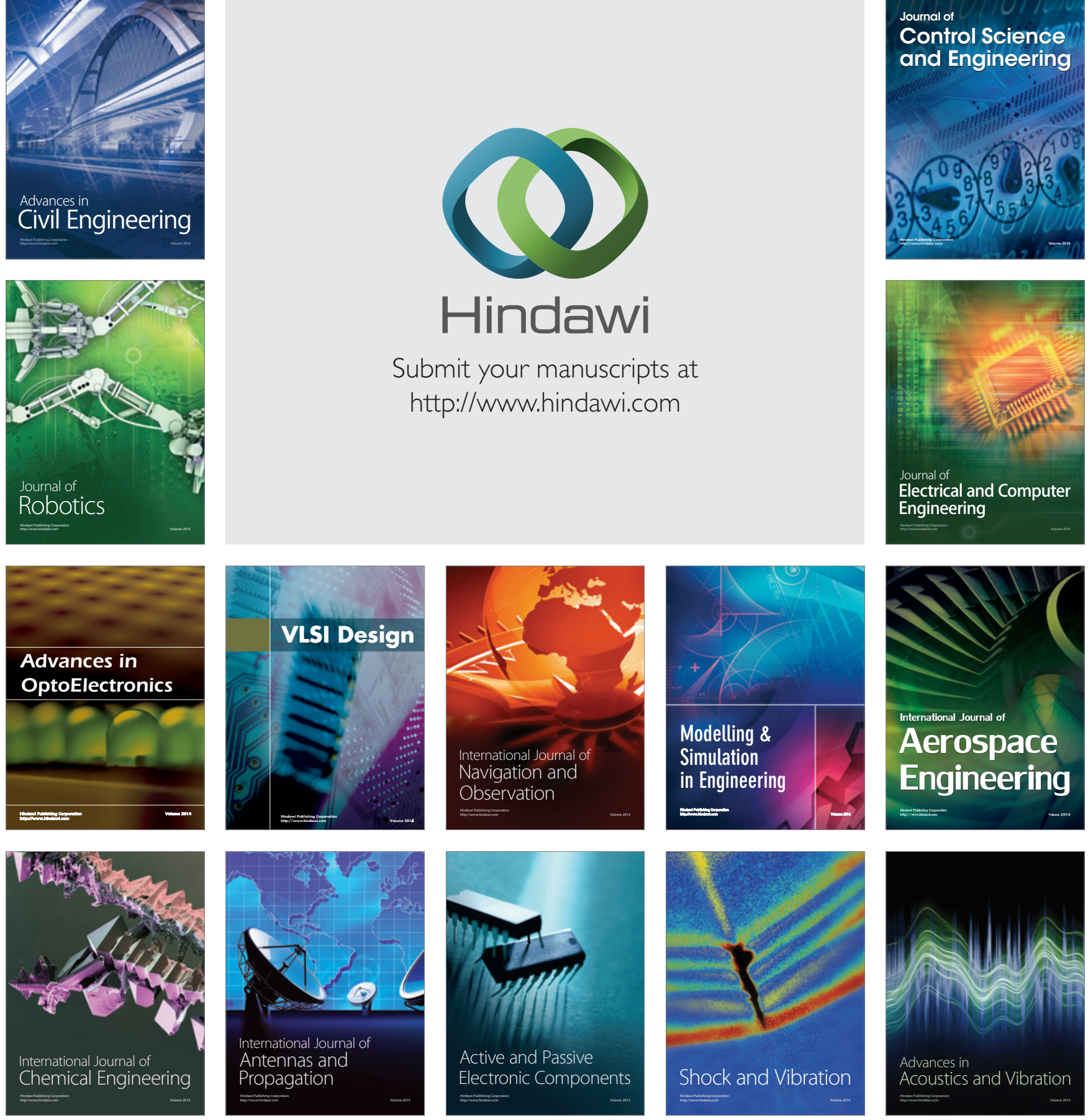